\title{
Genistein inhibits the S-phase kinase-associated protein 2 expression in breast cancer cells
}

\author{
DENGFENG YE, ZHIAN LI and CHUNSHOU WEI
}

Department of Oncological Surgery, The Second Hospital of Shaoxing, Shaoxing, Zhejiang 312000, P.R. China

Received May 1,2017; Accepted September 14, 2017

DOI: $10.3892 /$ etm.2017.5489

\begin{abstract}
Breast cancer is one of the most lethal cancers affecting women worldwide and was estimated to account for $\sim 30 \%$ of all new cancer diagnoses in women. Although available evidence has proved the tumor suppressor role of genistein in cancer, the underling mechanisms have remained to be fully elucidated. $\mathrm{S}$-phase kinase-associated protein 2 (Skp2) has been revealed to critically enhance the pathogenesis of multiple human cancers. The present study determined whether genistein exerts its anti-tumor function by suppressing Skp2 in breast cancer cells. Genistein significantly inhibited the proliferation, invasion and migration of breast cancer cells. Furthermore, genistein treatment also induced marked apoptosis and a typical cell cycle arrest in G2/M phase. Mechanistically, genistein treatment was identified to cause a significant downregulation of Skp2. Two crucial tumor suppressors, p21 and p27, were upregulated in genistein-treated breast cancer cells. The present results revealed that genistein exerted its tumor suppressor effect at least partially via inhibition of Skp2 and promotion of its downstream targets $\mathrm{p} 21$ and $\mathrm{p} 27$. Therefore, inactivation of Skp2 by genistein may be a promising approach for breast cancer treatment.
\end{abstract}

\section{Introduction}

Breast cancer is one of the most commonly diagnosed cancers in women and accounts for $30 \%$ of all new cancer diagnoses in women (1). An estimate of 252,710 patients are expected to be newly diagnosed with breast cancer in the US in 2017 , and 40,610 patients will die from this disease (1). Accumulated data have demonstrated that certain molecular signaling pathways contribute to the development and progression of breast carcinoma. For instance, in breast tumors, constitutive activation of nuclear factor $(\mathrm{NF})-\kappa \mathrm{B}$ was reported to contribute

Correspondence to: Dr Chunshou Wei, Department of Oncological Surgery, The Second Hospital of Shaoxing, 123 Yanan Road, Shaoxing, Zhejiang 312000, P.R. China

E-mail: chunshouwei@sina.com

Key words: genistein, breast cancer, S-phase kinase associated protein 2, apoptosis, proliferation to cellular proliferation, angiogenesis and evasion of apoptosis (2). The expression of members of the Sonic Hedgehog pathway was identified to be increased in MCF-7 breast cancer mammospheres in comparison to that in MCF-7 cells cultured as monolayers (3). Ibrahim et al (4) reported that the Notch and epidermal growth factor receptor signaling pathways are involved in syndecan-1-mediated modulation of cancer stem cell phenotypes of inflammatory breast cancer. In breast cancer, Wnt signaling is constitutively activated by an autocrine mechanism. In accordance with this, a study by Jang et al (5) reported that Wnt signaling is associated with the maintenance of stem cell properties and that blockade of Wnt/ $\beta$-catenin signaling suppresses in vitro and in vivo tumor formation and cellular migration.

S-phase kinase associated protein 2 ( $\mathrm{Skp} 2)$ has been reported to regulate cellular senescence, cancer progression and metastasis (6). It is an E3 ubiquitin ligase that belongs to the ubiquitin proteasome system and has emerged as an important factor in tumorigenesis due to the deregulated ubiquitination and proteolysis of its substrates (7). Skp2 was reported to be an oncoprotein and regulates the cell cycle, proliferation, differentiation, apoptosis and metastasis of a variety of human cancer types (7-9). In breast cancers, Skp2 has been revealed to promote carcinogenesis and cancer progression (10-12), rendering Skp2 a potential therapeutic target to combat breast cancer.

4',5,7-trihydroxyisoflavone (genistein) is a biologically active small molecule that is highly abundant in soy and soy products (13). This important compound is well known to inhibit cancer progression. In particular, genistein has emerged as an important inhibitor of cancer metastasis (14). It has been reported that genistein decreases cyclin B1 and induces p21, leading to cell cycle arrest of breast carcinoma cells in G2/M phase (15). Valachovicova et al (16) reported that genistein suppresses breast cancer cell adhesion and migration by inhibiting the constitutively activated transcription factors $\mathrm{NF}-\kappa \mathrm{B}$ and activator protein (AP)-1. It was also reported that genistein treatment increased the expression of p21 and p16 in breast cancer cells, and a genistein-rich diet inhibited the development of breast cancer xenografts in mice (17). Due to its important role in tumorigenesis, the potential of genistein as a promising therapeutic inhibitor of metastasis is highlighted.

The present study assessed the effects of genistein on cell proliferation, apoptotic cell death, cell cycle distribution, migration and invasion of breast cancer cells. The underling 
mechanisms of the antineoplastic activity of genistein in breast cancer were also investigated. Specifically, it was explored whether genistein exerted its anti-tumor effect in breast cancer cells via inhibition of Skp2.

\section{Materials and methods}

Cell culture and reagents. The MDA-MB-231 and SKBR3 human breast cancer cell lines were cultured in Dulbecco's modified Eagle's medium (DMEM, Gibco; Thermo Fisher Scientific, Inc., Waltham, MA, USA) supplemented with $10 \%$ fetal bovine serum (FBS; Invitrogen; Thermo Fisher Scientific, Inc.), penicillin (100 U/ml) and streptomycin $(100 \mathrm{U} / \mathrm{ml})$ in a humidified atmosphere containing $5 \% \mathrm{CO}_{2}$ at $37^{\circ} \mathrm{C}$. Genistein, calcein-acetoxymethyl (AM) and MTT were purchased from Sigma-Aldrich (Merck KGaA, Darmstadt, Germany). An Annexin V-FITC/PI Apoptosis Detection Kit, Transwell inserts and Matrigel were purchased from BD Biosciences (Franklin Lakes, NJ, USA). Primary antibody against tubulin (cat no. SC-5274) was purchased from Santa Cruz Biotechnology, Inc. (Dallas, TX, USA). Anti-p21 (cat no. 2946), anti-Skp2 (cat no. 4358), and anti-p27 (cat no. 2552) antibodies were obtained from Cell Signaling Technology, Inc. (Danvers, MA, USA). Anti-mouse HRP-linked antibody (cat no. 7076) and anti-rabbit HRP-linked antibody (cat no. 7074) were purchased from Cell Signaling Technology, Inc.

MTT assay. Cells were seeded at $5 \times 10^{3}$ cells/well in a 96-well plate and cultured overnight. Subsequently, the cells were treated with different concentrations of genistein. After 48 and $72 \mathrm{~h}, 10 \mu \mathrm{l}$ MTT solution $(5 \mathrm{mg} / \mathrm{ml})$ was added to each well, followed by incubation for at $37^{\circ} \mathrm{C}$ for $4 \mathrm{~h}$. Subsequently, the supernatant was discarded and $100 \mu 1$ dimethyl sulfoxide was added to dissolve the MTT-formazan crystals. The cell viability was evaluated by measuring the absorption of each well at $490 \mathrm{~nm}$ using a microplate reader.

Analysis of cell apoptosis. Cells were seeded at $1 \times 10^{5}$ cells/well in a six-well plate, cultured overnight and then treated with 20 or $40 \mu \mathrm{M}$ genistein for $48 \mathrm{~h}$. Cells were then harvested and washed with PBS, resuspended in $500 \mu \mathrm{l}$ binding buffer containing $5 \mu \mathrm{l}$ propidium iodide (PI) and $5 \mu \mathrm{l}$ fluorescein isothiocyanate (FITC)-conjugated Annexin V antibody in the dark for 15 min using a Dead Cell Apoptosis kit with Annexin V FITC and PI (cat. no. V13242; Thermo Fisher Scientific, Inc.). Genistein-induced breast cancer cell apoptosis was analyzed using a FACSCalibur flow cytometer (BD Biosciences).

Cell cycle analysis. Breast cancer cells in the exponential growth phase cells were seeded in a 6-well plate at $2.5 \times 10^{5}$ cells/well. After incubation overnight, the cells were treated with 20 or $40 \mu \mathrm{M}$ genistein for $48 \mathrm{~h}$. Cells were collected, washed with cold PBS and then fixed with ice-cold ethanol $70 \%(\mathrm{v} / \mathrm{v})$, in which they were kept at $4^{\circ} \mathrm{C}$ overnight. Prior to analysis, the cells were washed with cold PBS, re-suspended at $1 \times 10^{6}$ cells $/ \mathrm{ml}$ and stained with PBS containing $0.1 \mathrm{mg} / \mathrm{ml}$ RNase I (Invitrogen; Thermo Fisher Scientific, Inc.) and $50 \mathrm{mg} / \mathrm{ml}$ PI. After staining for $30 \mathrm{~min}$ at room temperature in the dark, the cell cycle was determined using a FACSCalibur flow cytometer (BD Biosciences).
Wound healing assay. Breast cancer cells were seeded and cultured in a 6-well plate. After the cells reached almost 100\% confluency, the cell monolayers were scraped with a pipette tip to generate linear scratch wounds. The detached cells were rinsed off with PBS and then supplemented with medium (without FBS) containing genistein. Images of the wounds were captured at 0 and $16 \mathrm{~h}$.

Transwell migration and invasion assay. Breast cancer cells $\left(1 \times 10^{4}\right.$ cells/well) were cultured in each of the upper chambers of Transwell without Matrigel (for migration assay) or Matrigel-precoated inserts (for invasion assay) in $200 \mu \mathrm{l}$ serum-free DMEM with genistein. In the lower chambers, $500 \mu \mathrm{l}$ complete medium containing 10\% FBS and the same concentration of genistein was added. After $24 \mathrm{~h}$ of incubation, the cells that had invaded through the pores and attached to the bottom surface of the membrane were stained with calcein-AM. Images of the stained invaded cells were captured under a fluorescent microscope.

Western blot analysis. Cells were harvested and resuspended in protein lysis buffer (Cell Signaling Technologies, Inc.). The protein samples were quantified using a Bicinchoninic Acid Protein assay kit (Thermo Fisher Scientific, Inc.) and heated for $5 \mathrm{~min}$ at $100^{\circ} \mathrm{C}$. Equal amounts of protein $(30 \mu \mathrm{g})$ were then separated by $10 \%$ SDS-PAGE. The decentralized proteins were transferred onto a polyvinylidene difluoride membrane (EMD Millipore, Billerica, MA, USA) and immunoblotted with the appropriate primary antibodies (anti-Skp2, 1:1,000 dilution; anti-p21 and anti-p27, 1:500 dilution) at $4^{\circ} \mathrm{C}$ overnight. After washing with Tris-buffered saline containing Tween-20, the membrane was probed with secondary antibodies (anti-mouse HRP-linked antibody, 1:5,000; anti-rabbit HRP-linked antibody, 1:5,000) and incubated at room temperature for $1 \mathrm{~h}$. Enhanced chemiluminescence (Thermo Fisher Scientific, Inc.) was then used to detect the expression of the proteins.

Statistical analysis. Statistical analysis was performed using GraphPad Prism 4.0 (Graph Pad Software, Inc., La Jolla, CA, USA). One-way analysis of variance was performed followed by a Dunnett's test to assess statistical significance. Values are expressed as the mean \pm standard error of the mean. $\mathrm{P}<0.05$ was considered to indicate a statistically significant difference.

\section{Results}

Genistein suppresses breast cancer cell proliferation. To determine whether genistein suppresses breast cancer cell proliferation, MDA-MB-231 and SKBR3 cells treated with different concentrations of genistein for 48 or $72 \mathrm{~h}$ were subjected to an MTT assay. The results indicated that genistein significantly suppressed cell proliferation in time- and dose-dependent manner (Fig. 1). In particular, treatment of each cell line with 20 and $40 \mu \mathrm{M}$ genistein led $\sim 40$ and $60 \%$ cell growth inhibition at $72 \mathrm{~h}$, respectively. Therefore, genistein was used at used at 20 and $40 \mu \mathrm{M}$ concentrations in the subsequent assays.

Genistein induces breast cancer cell apoptosis. It was further determined whether genistein-induced cell growth inhibition 
A

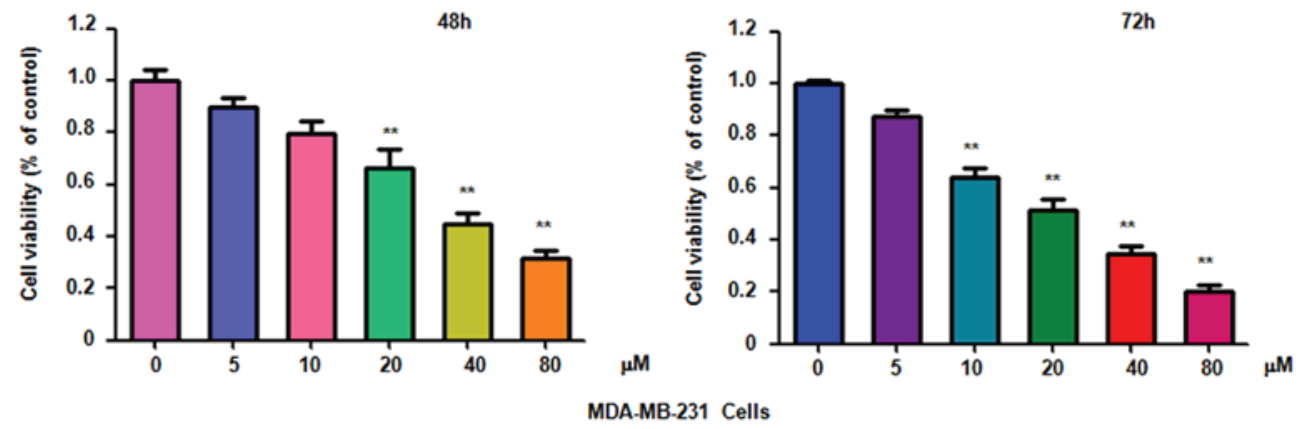

B
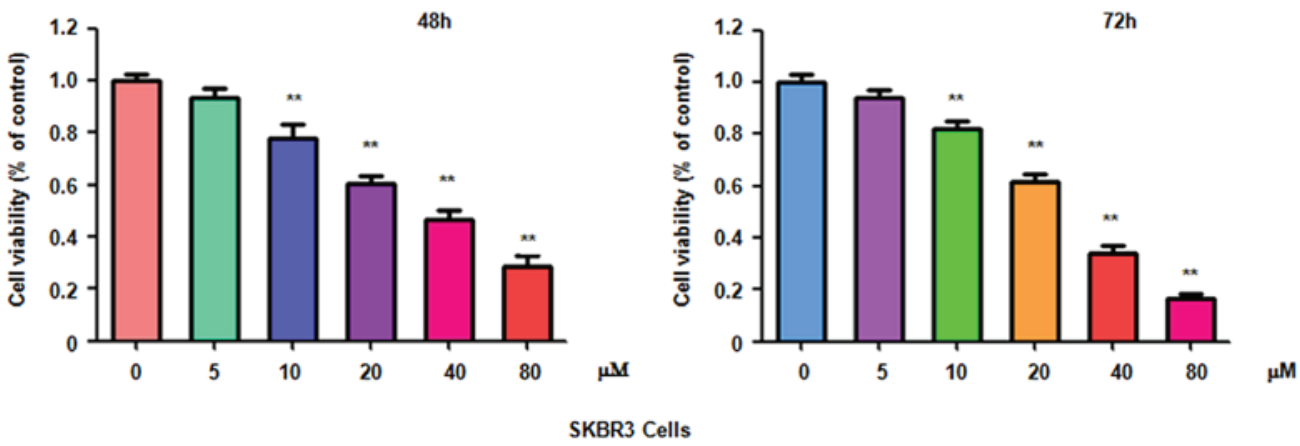

Figure 1. Genistein inhibits breast cancer cell growth. The proliferation of (A) MDA-MB-231 cells and (B) SKBR3 cells was detected by an MTT assay after treatment with genistein for 48 or $72 \mathrm{~h}$. ${ }^{* *} \mathrm{P}<0.001$ vs. control group.

is due to induction of cell apoptosis. Thus, after treatment with 20 and $40 \mu \mathrm{M}$ genistein for $48 \mathrm{~h}$, a PI-FITC-Annexin $\mathrm{V}$ assay was performed to detect the rate of apoptotic cell death in the two breast cell lines. It was revealed that genistein treatment significantly induced cell apoptosis in a dose-dependent manner (Fig. 2). The results indicated that genistein stimulated apoptosis in breast cancer cells, which was therefore partly responsible for the observed inhibition of cell proliferation induced by genistein.

Genistein induces cell cycle arrest in breast cancer cells. Next, it was assessed whether genistein modulates cell cycle arrest in MDA-MB-231 and SKBR3 cells after treatment with genistein. PI staining and flow cytometric analysis were performed for each of the two breast cancer cell lines. It was observed that genistein treatment caused cell cycle arrest in $\mathrm{G} 2 / \mathrm{M}$ phase in a dose-dependent manner (Fig. 3). In MDA-MB-231 cells, treatment with 0,20 and $40 \mu \mathrm{M}$ genistein led to an increase in the G2/M phase population from 7.51 to 16.17 and $41.72 \%$, respectively (Fig. 3A). A similar G2/M phase arrest was observed in SKBR3 cells after genistein treatment (Fig. 3B). These results demonstrate that genistein induced cell cycle arrest in $\mathrm{G} 2 / \mathrm{M}$ phase in the two breast cancer cell lines.

Genistein inhibits breast cancer cell migration. It was then assessed whether genistein inhibits breast cancer cell migration. The MDA-MB-231 and SKBR3 cell lines treated with genistein were subjected to a wound healing assay. The results indicated that in each of the two cell lines, genistein treatment significantly suppressed cell migratory activity in a dose-dependent manner ( $\mathrm{P}<0.05$; Fig. 4). Consistent with this, the Transwell assay also indicated that genistein inhibited cell migration in breast cancer cells (Fig. 5).
Genistein inhibits breast cancer cell invasion. In order to further assess whether genistein inhibits the invasion potential of breast cancer cells, a Transwell invasion assay was performed. The cells that had migrated through the pores of the matrigel-coated membranes were significantly decreased in each of the two genistein-treated breast cancer cell lines (Fig. 5). This result indicated that genistein reduces the invasive potential of breast cancer cells.

Genistein suppresses Skp2 expression in breast cancer cells. Accumulated evidence has characterized Skp2 as an oncoprotein in breast cancer and suppression of Skp2 may be a promising target for the treatment of breast cancer (7). The present study explored whether genistein suppresses Skp2 expression in breast cancer cells. Western blot analysis results demonstrated a significantly decreased expression of Skp2 in genistein-treated breasted cancer cells (Fig. 6). Furthermore, the protein levels of p21 and p27, two typical downstream targets of Skp2, were increased after genistein treatment (Fig. 6). These results confirm that genistein exerts its anti-tumor activity in breast cancer cells at least partially by suppressing Skp2 expression.

\section{Discussion}

Breast cancer is one of the most lethal cancer types affecting women and represents the second leading cause of cancer-associated mortality in women (1). However, as the precise pathogenic factors remain to be fully elucidated, the development of effective measures of prevention and treatment methods for breast cancer remain a significant challenge. Over the past decades, abundant research has verified numerous natural products obtained from 
A

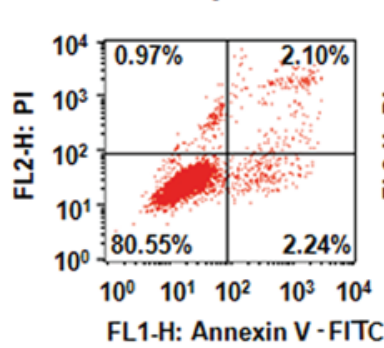

B

0

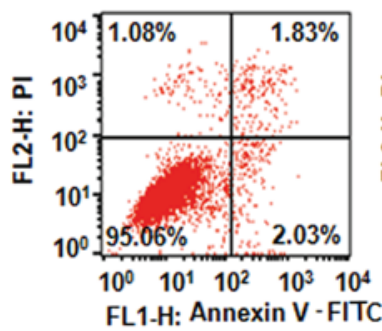

C

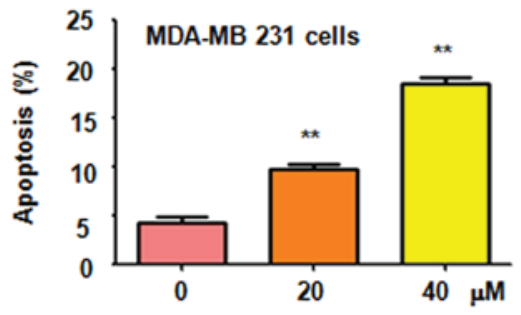

$20 \mu \mathrm{M}$

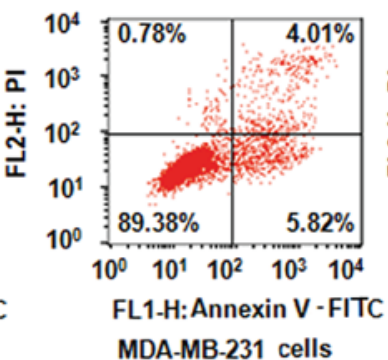

$20 \mu \mathrm{M}$

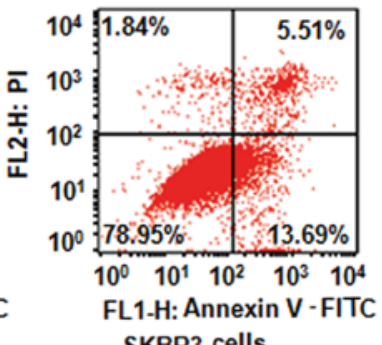

SKBR3 cells

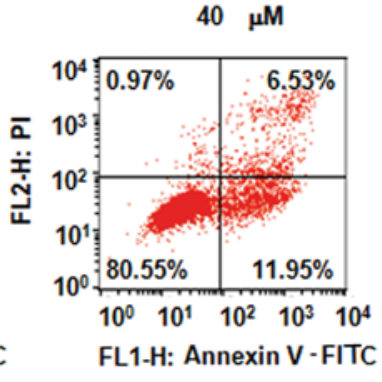

$40 \mu \mathrm{M}$

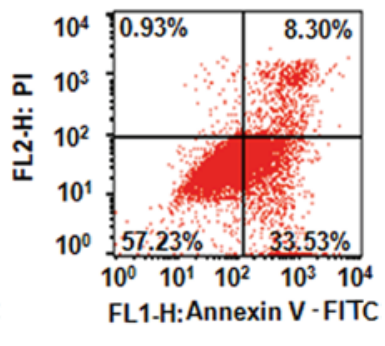

Figure 2. Genistein promotes apoptosis of breast cancer cells. The effect of genistein on the apoptosis of (A) MDA-MB-231 cells and (B) SKBR3 breast cancer cells was accessed by flow cytometry. (C) Quantification of A and B provided the apoptotic rates. ${ }^{* *}$ P $<0.01$ vs the control group. PI, propidium iodide; FITC, fluorescein isothiocyanate.

A

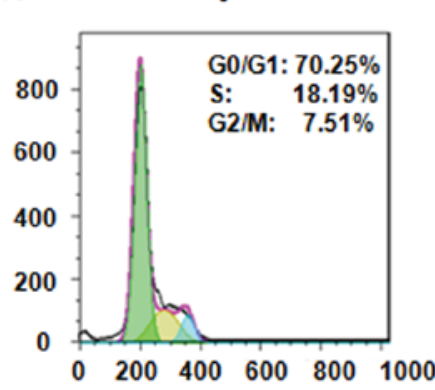

B

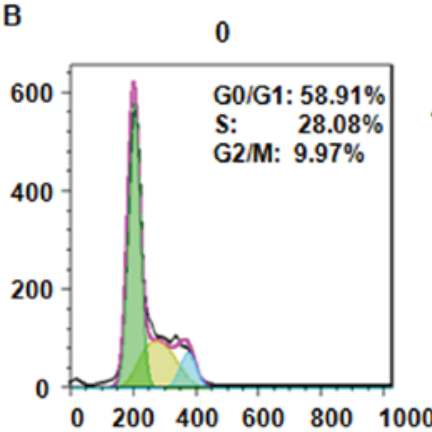

$20 \mu \mathrm{M}$

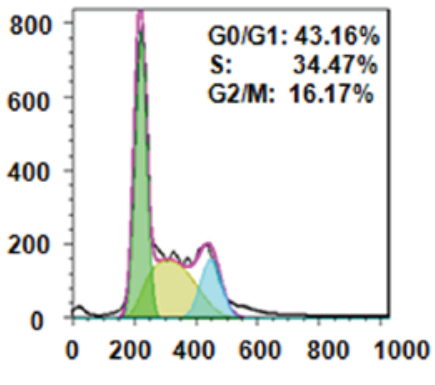

MDA-MB-231 Cells

$20 \mu \mathrm{M}$

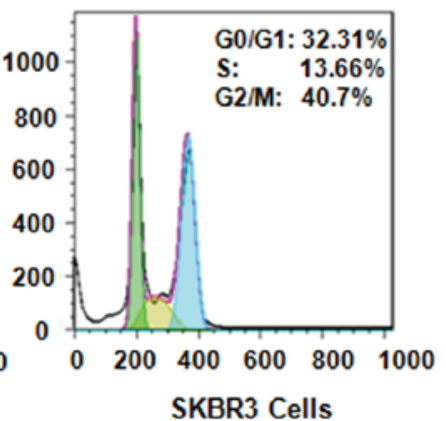

$40 \mu \mathrm{M}$

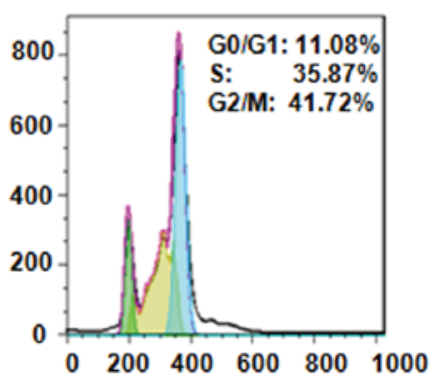

$40 \mu \mathrm{M}$

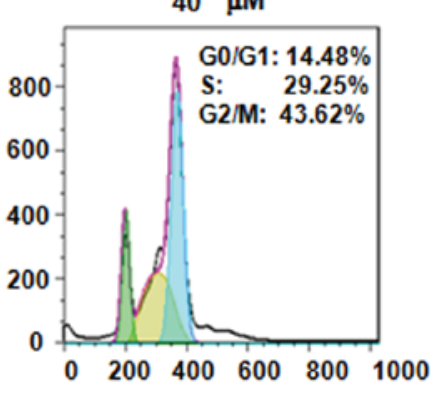

Figure 3. Genistein induces cell cycle arrest of breast cancer cells in G2/M phase. The effect of genistein on the cell cycle distribution of (A) MDA-MB-231 cells and (B) SKBR3 cells was measured by flow cytometry. The X-axis displays the DNA content and the Y-axis the cell count. 
A

oh

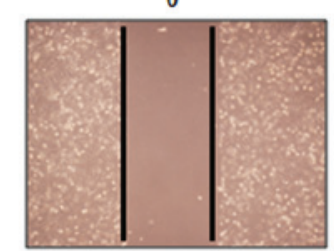

$16 \mathrm{~h}$

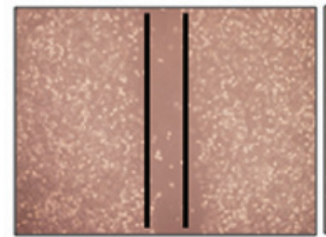

$20 \mu \mathrm{M}$
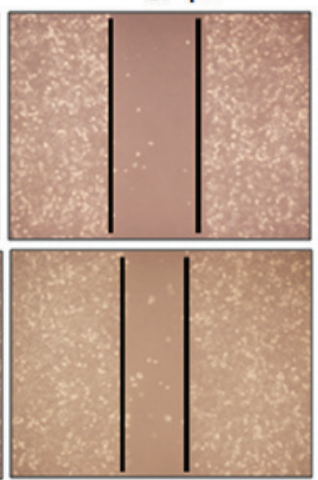

MDA-MB-231 Cells

B
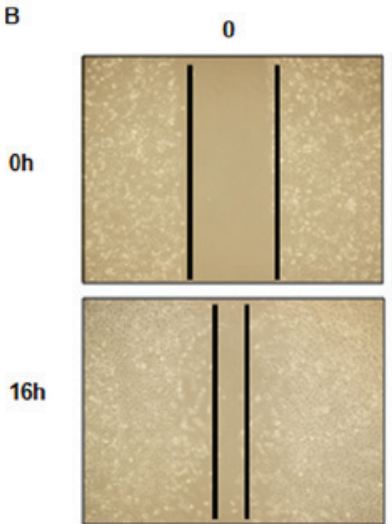
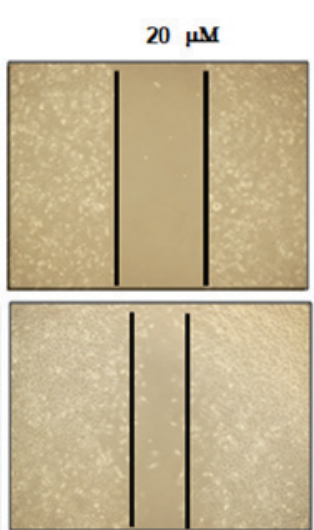

SKBR3 Cells
$40 \mu \mathrm{M}$

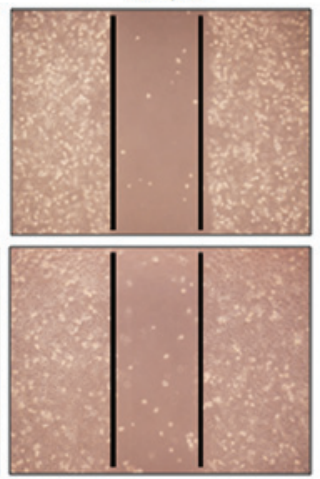

$40 \mu \mathrm{M}$
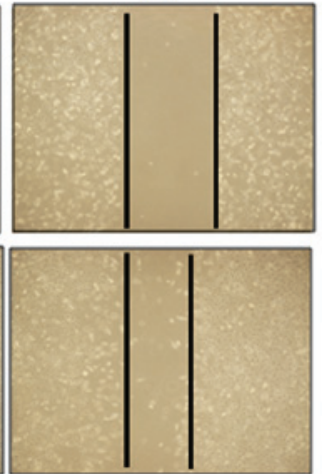
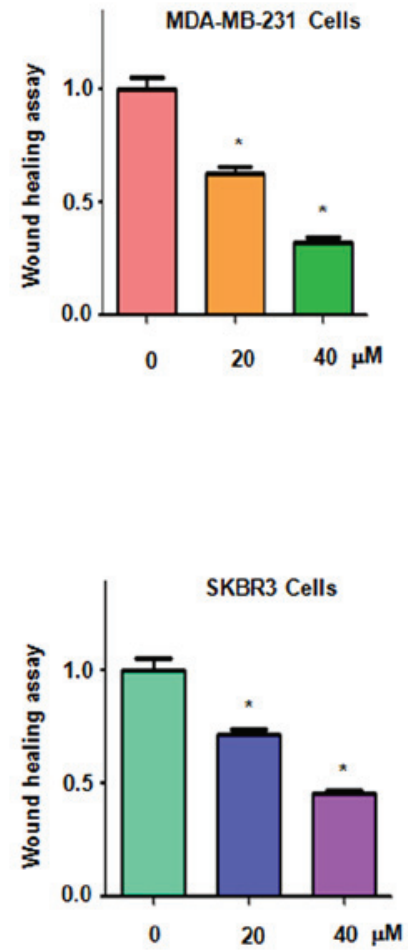

Figure 4. Genistein suppresses breast cancer cell migration. At $16 \mathrm{~h}$ after genistein or control treatment, the migration ability of (A) MDA-MB-231 cells and (B) SKBR3 cells was measured by a wound healing assay. Magnification, $\mathrm{x} 40 .{ }^{*} \mathrm{P}<0.05$ vs. control group.

A

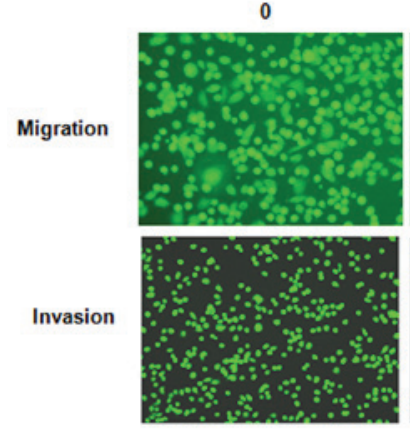

B

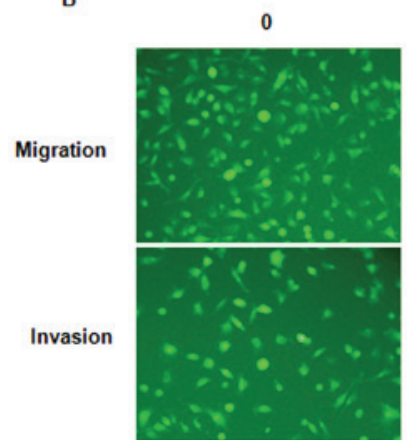

$20 \mu \mathrm{M}$
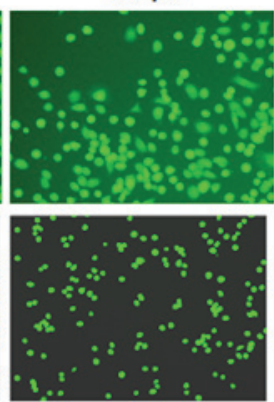

MDA-MB-231 Cells

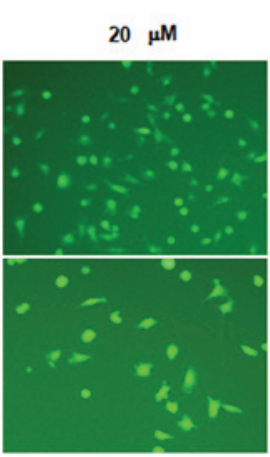

SKBR3 Cells
$40 \mu \mathrm{M}$

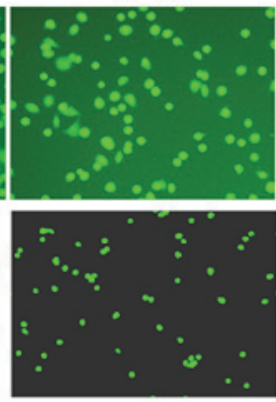

$40 \mu \mathrm{M}$

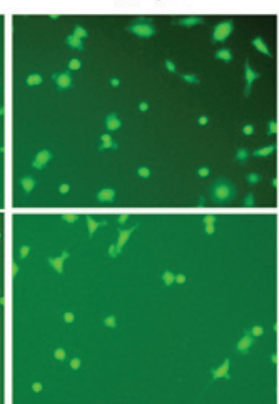

1.

Figure 5. Genistein inhibits breast cancer cell migration and invasion. The effect of genistein on the invasion potential of (A) MDA-MB-231 cells and (B) SKBR3 cells was detected by a Transwell assay Cells were stained with calcein-AM. Images of the stained invaded cells were captured under a fluorescent microscope. Magnification, $\mathrm{x} 40$. 
A

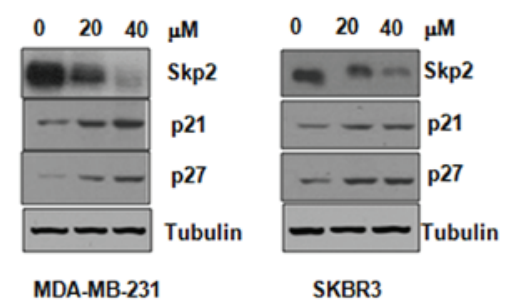

B
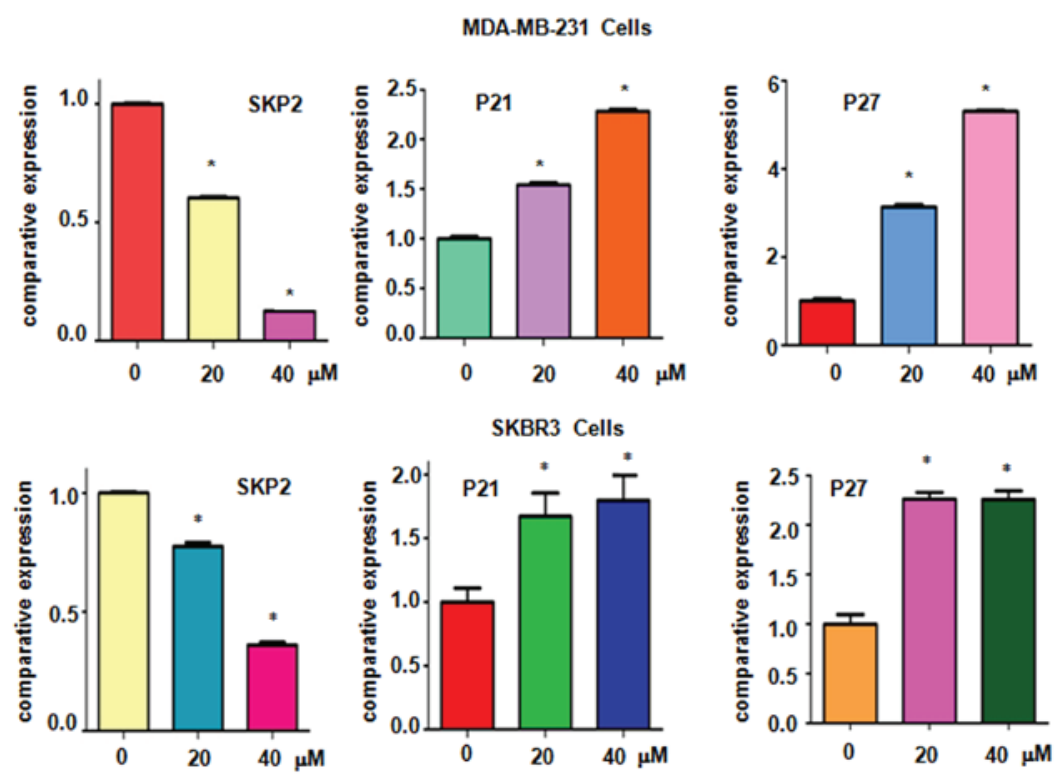

Figure 6. Genistein suppresses Skp2 expression. (A) The expression of Skp2 and its downstream targets, p21 and p27, was detected by western blot analysis in genistein-treated MDA-MB-231 cells (left panel) and SKBR3 cells (right panel). (B) Quantitative expression levels determined by densitometric evaluation of the immunoblot images. ${ }^{*} \mathrm{P}<0.05$ vs. control group. Skp2, S-phase kinase-associated protein 2.

dietary sources, which have potential chemopreventive and anti-cancer effects (18). In general, higher intake of soy products has been associated with lower risk of breast cancer, particularly in Asian countries (19). Genistein, a major active component of soy isoflavones, is thought to be a potent chemopreventive and therapeutic agent for breast cancer (20). However, it should be noted that it has also been indicated that genistein is associated with breast cancer development (20). Accumulating evidence has suggested that genistein acts as a multi-targeting antitumor agent in a variety of human cancer types (21). Early studies have revealed that genistein exerts its effects of phytoestrogen, tyrosine kinase and topoisomerase inhibition by directly binding to the estrogen receptor (22), receptor tyrosine kinase (23) and topoisomerase (24). With regard to its antitumor function, genistein was identified to modulate numerous key signaling molecules, including NF-kB, caspase-3, p38 mitogen-activated protein kinase and phosphoinositide 3 kinase/Akt to induce growth inhibition and apoptosis $(16,25,26)$. Genistein also suppressed matrix metalloproteinase- 9 transcription by inhibiting the activity of AP-1 and NF- $\mathrm{KB}$, which restrained the invasiveness and metastatic potential of hepatocellular carcinoma cells (26). Genistein was also demonstrated to suppress cancerous inhibitor of protein phosphatase $2 \mathrm{~A}$, a newly identified oncogene frequently overexpressed in breast cancer, which contributed to its growth inhibitory and apoptosis-inducing effects (27). Li et al (17) revealed that genistein treatment significantly suppressed breast cancer cell growth, increased the expression of the two crucial tumor inhibitor genes p21 and p16, and decreased the two important tumor promoting genes BMI1 and c-MYC. In addition, an in vivo experiment suggested that the development of breast cancer xenografts in mice was effectively inhibited by the intake of a genistein-rich diet (17). It was suggested that genistein represses early breast tumorigenesis by epigenetic regulation of $\mathrm{p} 21$ and p16. Consistent with these results, the present study observed that genistein significantly inhibited breast cancer cell growth, migration and invasion, and induced apoptosis in a dose-dependent manner. Two crucial tumor suppressors, p21 and p27, were markedly upregulated in genistein-treated breast cancer cells.

Available evidence suggests that Skp2 has important roles in cell growth, apoptosis, invasion and metastasis, and is a predictive factor for poor prognosis in human breast cancer (12). Thus, inactivation of Skp2 may be a promising therapeutic strategy for breast cancer treatment. Of note, several Skp2 inhibitors, including Compound A and Compound 25, were reported to block Skp2 E3 ligase activity $(28,29)$. However, chemical inhibitors tend to exhibit side effects during treatment, which are difficult to overcome. Therefore, natural agents with innoxious properties and the ability to inactivate Skp2 in human cancers are of great interest. Several natural agents, including flavokawain A (30), chrysin (31), curcumin (32,33), butylidenephthalide (34) and rottlerin $(35,36)$, have been identified to downregulate Skp2 in various types of human cancer. The present study reported on another natural product, genistein, which had a potent 
inhibitory effect on Skp2 expression in breast cancer cells. The results suggested that inactivation of Skp2 may, at least partially, contribute to the anticancer effect of genistein. Therefore, inactivation of Skp2 by genistein may be utilized for the clinical treatment of breast cancer. However, it is necessary to explore the precise molecular mechanisms of genistein-induced inhibition of Skp2. More importantly, the anti-breast cancer effects of genistein should be assessed in an animal model and a clinical trial should be performed in the future.

\section{References}

1. Siegel RL, Miller KD and Jemal A: Cancer statistics. CA Cancer J Clin 67: 7-30, 2017.

2. Liu M, Sakamaki T, Casimiro MC, Willmarth NE, Quong AA, Ju X, Ojeifo J, Jiao X, Yeow WS, Katiyar S, et al: The canonical NF-kappaB pathway governs mammary tumorigenesis in transgenic mice and tumor stem cell expansion. Cancer Res 70: 10464-10473, 2010

3. He M, Fu Y, Yan Y, Xiao Q, Wu H, Yao W, Zhao H, Zhao L, Jiang Q, Yu Z, et al: The Hedgehog signalling pathway mediates drug response of MCF-7 mammosphere cells in breast cancer patients. Clin Sci (Lond) 129: 809-822, 2015

4. Ibrahim SA, Gadalla R, El-Ghonaimy EA, Samir O, Mohamed HT, Hassan H, Greve B, El-Shinawi M, Mohamed MM and Götte M: Syndecan-1 is a novel molecular marker for triple negative inflammatory breast cancer and modulates the cancer stem cell phenotype via the IL-6/STAT3, Notch and EGFR signaling pathways. Mol Cancer 16: 57, 2017.

5. Jang GB, Kim JY, Cho SD, Park KS, Jung JY, Lee HY, Hong IS and Nam JS: Blockade of Wnt/ $\beta$-catenin signaling suppresses breast cancer metastasis by inhibiting CSC-like phenotype. Sci Rep 5: 12465, 2015

6. Wang G, Chan CH, Gao Y and Lin HK: Novel roles of Skp2 E3 ligase in cellular senescence, cancer progression and metastasis Chin J Cancer 31: 169-177, 2012.

7. Frescas D and Pagano M: Deregulated proteolysis by the F-box proteins SKP2 and beta-TrCP: Tipping the scales of cancer. Nat Rev Cancer 8: 438-449, 2008.

8. Wang Z, Liu P, Inuzuka H and Wei W: Roles of F-box proteins in cancer. Nat Rev Cancer 14: 233-247, 2014.

9. Chan CH, Morrow JK, Zhang S and Lin HK: Skp2: A dream target in the coming age of cancer therapy. Cell Cycle 13: 679-680, 2014

10. Zhang W, Cao L, Sun Z, Xu J, Tang L, Chen W, Luo J, Yang F, Wang Y and Guan X: Skp2 is over-expressed in breast cancer and promotes breast cancer cell proliferation. Cell Cycle 15 1344-1351, 2016

11. Yang C, Nan H, Ma J, Jiang L, Guo Q, Han L, Zhang Y, Nan K and Guo H: High Skp2/Low p57(Kip2) expression is associated with poor prognosis in human breast carcinoma. Breast Cancer (Auckl) 9 (Suppl 1): S13-S21, 2015.

12. Wang Z, Fukushima H, Inuzuka H, Wan L, Liu P, Gao D, Sarkar FH and Wei W: Skp2 is a promising therapeutic target in breast cancer. Front Oncol 1: 2012

13. Messina M, Nagata C and Wu AH: Estimated Asian adult soy protein and isoflavone intakes. Nutr Cancer 55: 1-12, 2006.

14. Pavese JM, Farmer RL and Bergan RC: Inhibition of cancer cell invasion and metastasis by genistein. Cancer Metastasis Rev 29: 465-482, 2010.

15. Choi YH, Zhang L, Lee WH and Park KY: Genistein-induced $\mathrm{G} 2 / \mathrm{M}$ arrest is associated with the inhibition of cyclin B1 and the induction of p21 in human breast carcinoma cells. Int J Oncol 13: 391-396, 1998

16. Valachovicova T, Slivova V, Bergman H, Shuherk J and Sliva D: Soy isoflavones suppress invasiveness of breast cancer cells by the inhibition of NF-kappaB/AP-1-dependent and -independent pathways. Int J Oncol 25: 1389-1395, 2004.

17. Li Y, Chen H, Hardy TM and Tollefsbol TO: Epigenetic regulation of multiple tumor-related genes leads to suppression of breast tumorigenesis by dietary genistein. PLoS One 8: e54369, 2013.

18. Bonofiglio D, Giordano C, De Amicis F, Lanzino M and Andò S Natural products as promising antitumoral agents in breast cancer: Mechanisms of action and molecular targets. Mini Rev Med Chem 16: 596-604, 2016.
19. Nagata C, Mizoue T, Tanaka K, Tsuji I, Tamakoshi A, Matsuo K, Wakai K, Inoue M, Tsugane S, Sasazuki S, et al: Soy intake and breast cancer risk: an evaluation based on a systematic review of epidemiologic evidence among the Japanese population. Jpn J Clin Oncol 44: 282-295, 2014.

20. Uifalean A, Schneider S, Ionescu C, Lalk M and Iuga CA: Soy Isoflavones and breast cancer cell lines: Molecular mechanisms and future perspectives. Molecules 21: E13, 2015.

21. Sarkar FH and Li Y: Mechanisms of cancer chemoprevention by soy isoflavone genistein. Cancer Metastasis Rev 21: 265-280, 2002.

22. Wang TT, Sathyamoorthy N and Phang JM: Molecular effects of genistein on estrogen receptor mediated pathways. Carcinogenesis 17: 271-275, 1996.

23. Akiyama T, Ishida J, Nakagawa $\mathrm{S}$, Ogawara $\mathrm{H}$, Watanabe $\mathrm{S}$, Itoh N, Shibuya M and Fukami Y: Genistein, a specific inhibitor of tyrosine-specific protein kinases. J Biol Chem 262: 5592-5595, 1987.

24. Corbett AH, Hong D and Osheroff N: Exploiting mechanistic differences between drug classes to define functional drug interaction domains on topoisomerase II. Evidence that several diverse DNA cleavage-enhancing agents share a common site of action on the enzyme. J Biol Chem 268: 14394-14398, 1993.

25. Shafiee G, Saidijam M, Tavilani H, Ghasemkhani N and Khodadadi I: Genistein induces apoptosis and inhibits proliferation of HT29 colon cancer cells. Int J Mol Cell Med 5: 178-191, 2016.

26. Wang SD, Chen BC, Kao ST, Liu CJ and Yeh CC: Genistein inhibits tumor invasion by suppressing multiple signal transduction pathways in human hepatocellular carcinoma cells. BMC Complement Altern Med 14: 26, 2014.

27. Zhao Q, Zhao M, Parris AB, Xing Y and Yang X: Genistein targets the cancerous inhibitor of PP2A to induce growth inhibition and apoptosis in breast cancer cells. Int J Oncol 49: 1203-1210, 2016

28. Chen Q, Xie W, Kuhn DJ, Voorhees PM, Lopez-Girona A, Mendy D, Corral LG, Krenitsky VP, Xu W, Moutouh-de Parseval L, et al: Targeting the p27 E3 ligase SCF(Skp2) results in p27- and Skp2-mediated cell-cycle arrest and activation of autophagy. Blood 111: 4690-4699, 2008.

29. Chan CH, Morrow JK, Li CF, Gao Y, Jin G, Moten A, Stagg LJ, Ladbury JE, Cai Z, Xu D, et al: Pharmacological inactivation of Skp2 SCF ubiquitin ligase restricts cancer stem cell traits and cancer progression. Cell 154: 556-568, 2013.

30. Jandial DD, Krill LS, Chen L, Wu C, Ke Y, Xie J, Hoang BH and $\mathrm{Zi} \mathrm{X}$ : Induction of G2M arrest by flavokawain A, a kava chalcone, increases the responsiveness of her2-overexpressing breast cancer cells to herceptin. Molecules 22: 2017.

31. Huang C, Wei YX, Shen MC, Tu YH, Wang CC and Huang HC: Chrysin, abundant in morinda citrifolia fruit water-etoac extracts, combined with apigenin synergistically induced apoptosis and inhibited migration in human breast and liver cancer cells. J Agric Food Chem 64: 4235-4245, 2016.

32. Su J, Zhou X, Wang L, Yin X and Wang Z: Curcumin inhibits cell growth and invasion and induces apoptosis through down-regulation of Skp2 in pancreatic cancer cells. Am J Cancer Res 6: 1949-1962, 2016.

33. Feng S, Wang Y, Zhang R, Yang G, Liang Z, Wang Z and Zhang G: Curcumin exerts its antitumor activity through regulation of miR-7/Skp2/p21 in nasopharyngeal carcinoma cells. Onco Targets Ther 10: 2377-2388, 2017.

34. Huang MH, Lin SZ, Lin PC, Chiou TW, Harn YW, Ho LI, Chan TM, Chou CW, Chuang CH, Su HL and Harn HJ: Brain tumor senescence might be mediated by downregulation of S-phase kinase-associated protein 2 via butylidenephthalide leading to decreased cell viability. Tumour Biol 35: 4875-4884, 2014.

35. Yin X, Zhang Y, Su J, Hou Y, Wang L, Ye X, Zhao Z, Zhou X, $\mathrm{Li} \mathrm{Y}$ and Wang $\mathrm{Z}$ : Rottlerin exerts its anti-tumor activity through inhibition of Skp2 in breast cancer cells. Oncotarget 7: 66512-66524, 2016.

36. Su J, Wang L, Yin X, Zhao Z, Hou Y, Ye X, Zhou X and Wang Z: Rottlerin exhibits anti-cancer effect through inactivation of $S$ phase kinase-associated protein 2 in pancreatic cancer cells. Am J Cancer Res 6: 2178-2191, 2016.

This work is licensed under a Creative Commons Attribution-NonCommercial-NoDerivatives 4.0 International (CC BY-NC-ND 4.0) License. 